\title{
Search Strategy for Buried Objects in Water: Geophysics, Probes and Dogs
}

\author{
Alastair Ruffell ${ }^{1, *}$ and Neil Powell ${ }^{2}$ \\ 1 School of Natural Built Environment, Queen's University, Belfast BT7 1NN, Northern Ireland, UK \\ 2 School of Biological Sciences, Queen's University, Belfast BT7 1NN, Northern Ireland, UK; \\ npowell01@qub.ac.uk \\ * Correspondence: a.ruffell@qub.ac.uk
}

Citation: Ruffell, A.; Powell, N. Search Strategy for Buried Objects in Water: Geophysics, Probes and Dogs. Forensic. Sci. 2021, 1, 130-137. https://doi.org/10.3390/ forensicsci1030012

Academic Editor: Aurea Carvalho

Received: 6 September 2021

Accepted: 3 October 2021

Published: 9 October 2021

Publisher's Note: MDPI stays neutral with regard to jurisdictional claims in published maps and institutional affiliations.

Copyright: (c) 2021 by the authors. Licensee MDPI, Basel, Switzerland. This article is an open access article distributed under the terms and conditions of the Creative Commons Attribution (CC BY) license (https:// creativecommons.org/licenses/by/ $4.0 /)$.
Abstract: The aqueous search for objects covered by sediment is a common and challenging problem. Here we outline a sequential methodology for the assessment of targets identified by sub-bottom profiling. This comprises desktop study of available data; background hydrological information gathering (bathymetry, sediment cover, water chemistry); acoustic sub-bottom imaging (waterpenetrating radar, sonar); geolocation and probing of sub-bottom anomalies; and deployment of suitable scent dogs. This procedure creates a hierarchy of targets for examination by dive teams and thence recovery.

Keywords: forensic science; ground-penetrating radar; underwater scenes of crime

\section{Background to the Issue}

Probes are commonly used in terrestrial search, both to assess ground conditions [1,2] and often conjunctively to vent gases for search dogs [3-5]. The search of aqueous environments for human remains [6] may seem a counterintuitive environment in which to use probes. However, archaeological studies such as in Winton (2019 [7] and in our water-search casework has consistently shown that a water-bottom object can be covered by sediment, precluding the use of underwater cameras and sonar and limiting the work of dive personnel. This may occur through natural processes of siltation, sedimentation accelerated by climate change, land use alterations [8], or intentionally at landfill sites and in rare cases by the perpetrator. Should the water-covered and sediment-buried object (e.g., a human cadaver [9]) degrade over time, then this problem of detection is exacerbated. Thus when standard water searches (divers, dogs, sonar) are inconclusive, yet background information (sometimes, 'intelligence' or offender profiling 'data'-author parentheses) is indicative of a water deposition site and thus the target covered by sediment, the only remaining options are the use of ground-penetrating radar (more correctly, water-penetrating radar [10]) or (as is seen frequently in news reports) draining of the site, then fingertip search/archaeological excavation.

\section{Example Case That Demonstrates the Issue}

In this case of accidental drowning in a lake in Ireland, a fisherman was reported missing in 2005. Background information from financial records moved the search of the lake to a missing persons enquiry involving possible fraud, as the man's transactions showed activity after his disappearance. These subsequently transpired to be erroneous (a relative was using his bank card), thus some four years after he went missing, a renewed search of the lake was made by the police and volunteer search teams, using sonar (Figure 1) and water-trained search dogs. The dogs consistently indicated a specific location in the lake, yet the sonar showed only sediment: a dive team was deployed, and using a fingertip search, came across fishing tackle (initially a float and line, which led to a rod). With further 
arm extension into the lake bottom silt, the body of the man was found and recovered: without the fortuitous discovery of the fishing tackle, this may never have been achieved.

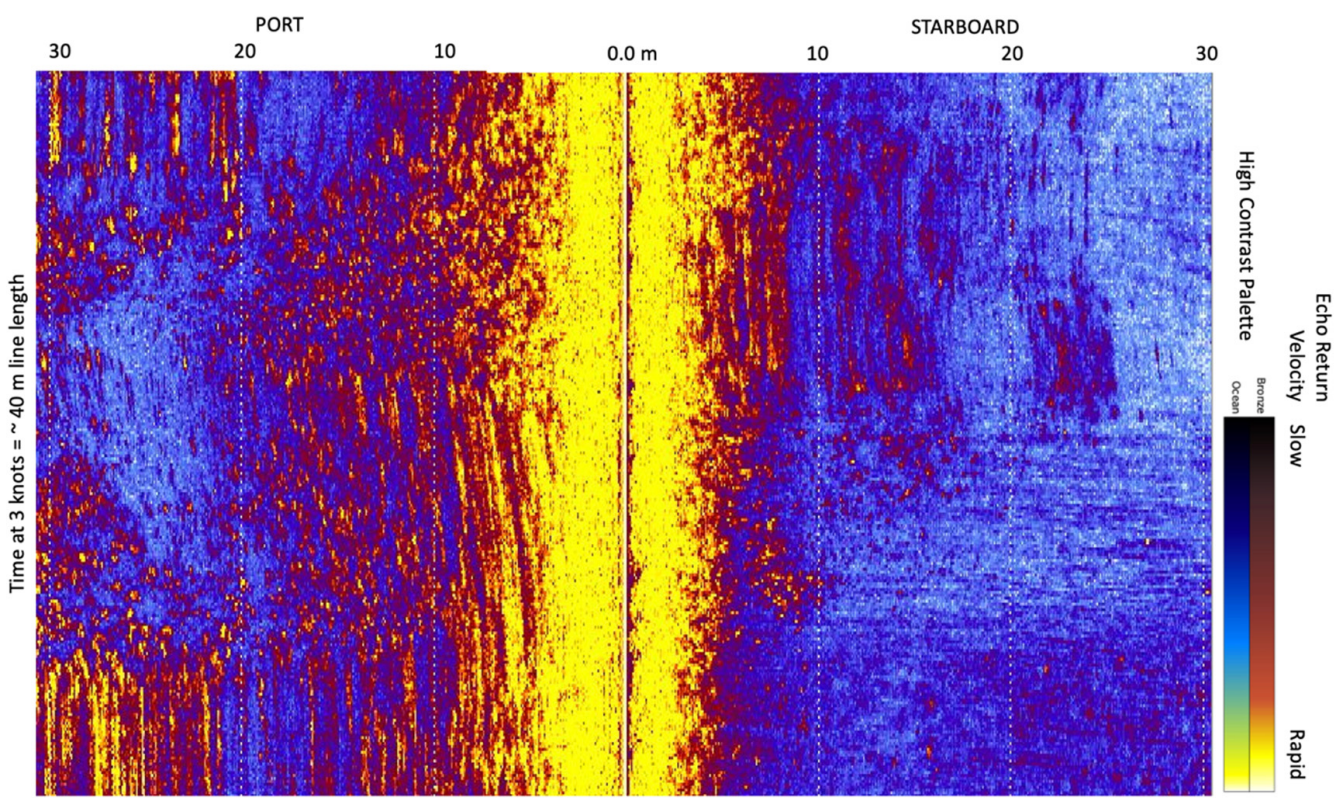

Figure 1. Example sonar image of a lake floor in Ireland, acquired during the search for a missing person (presumed drowned, search abandoned and later found). Silt and mud from autumn hinterland ploughing and coincident heavy rain (www.met.ie/climate/available-data/long-term-data-sets (accessed on 6 September 2021)) created a 30 to $90 \mathrm{~cm}$ sediment layer over the lake floor, except for the margins and some subaqueous springs. Data were acquired using a Starfish 990 Sonar: yellow-bronze indicates a more rapid echo return from upstanding sediment (ripples, small mounds that appear elongate from sonar movement) and directly under the tow-vessel; blue-green (ocean) indicates a slower echo return away from the tow-vessel and sediment hollows (may appear as troughs, due to sonar movement). No discrete object(s) are observed.

\section{Recommended Equipment and Methods}

When a search of water is initiated and sediment build-up is thought likely, or observed visually (in clear water by eye, or by underwater camera/sonar), then the possibility of a sub-sediment target maybe assumed if the background information is strong enough to warrant further searching. The initial stage in such an operation is completion of as full a desktop study as possible [11] including: solid/drift geology, hydrology, historic land use, recent land use (commonly, orthoimagery) and most critical for geophysics and probe use, bathymetry [12]. When the standard options of sonar (see above), dive teams and water-trained scent dogs are exhausted or too complex, then the methodology proposed here should be considered. First, some form of sediment profiling device(s) be it either acoustic [7], such as a sub-bottom profiler (e.g., GeoPulse or StataBox); CHIRPS (compressed high intensity radar pulse, for example, Edgetech or Pinger) when searching salt/brackish/fresh or polluted water, or water-penetrating radar (WPR - terrestrial radar such as Sensors \& Software, Mala Geoscience or GSSI placed in a suitable vessel [9]) in freshwater only. Such devices provide targets in the water column—but also most relevant here, in the sediment subsurface below: see Figure 2. 

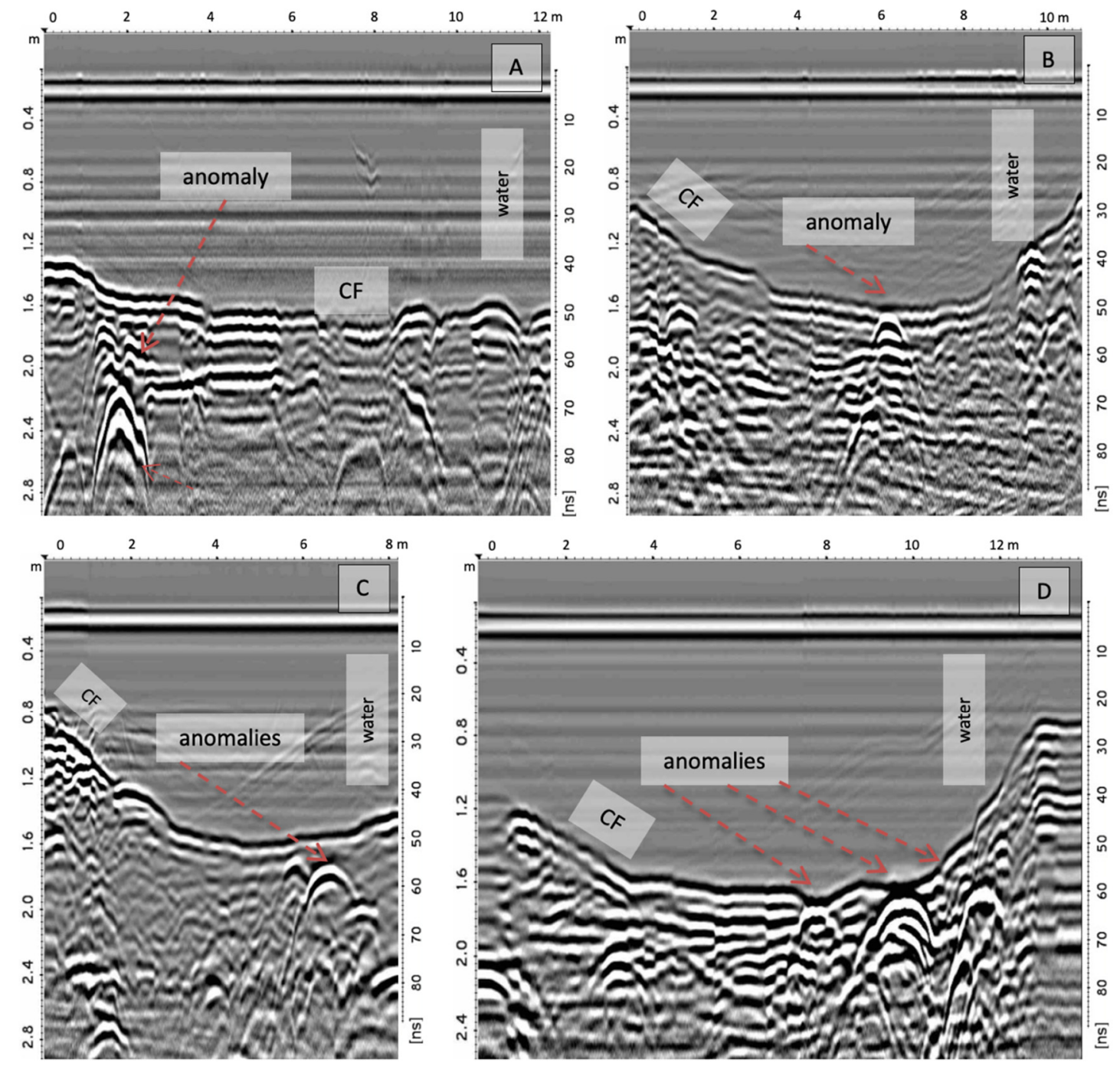

Figure 2. Water-penetrating radar profiles across a canal search location for a missing child, each WPR profile is from a separate survey profile: numerous sub-bottom anomalies occur (especially in Figure 2D). Data were gathered using the methodology of Ruffell \& Parker [9] wherein a 450 MHz Mala Geoscience High Dynamic Range GPR was placed (with the terrestrial-survey skid-plate removed) in an inflatable rib with no foot-slats and propelled by electric engine or shore-based personnel with ropes. Profiles depth converted using $0.032 \mathrm{~m} / \mathrm{ns}$, based on water conductivity measurements. $\mathrm{CF}=$ canal floor; $\mathrm{m}=$ metres; $\mathrm{ns}=$ nanoseconds (two-way time, right axis). (A) shows one bright anomaly, buried by $\sim 80 \mathrm{~cm}$ of sediment (cast iron part of canal boat); (B) shows one hyperbola, with a thin veneer of sediment (discarded paint can); (C) shows three adjacent anomalies-interpreted as possibly the same object with different parts (hessian sack with dog bones inside); (D) demonstrates the dilemma faced by those undertaking searches for human remains in freshwaternumerous anomalies (not retrieved, unknown origin). Repeated offset surveys over the anomalies shown demonstrated they were not out-of-plane, sediment-surface objects.

The problem is what to do with such multiple targets, such as we see in Figure 2. This leads to the second stage in the methodology: the use of the probe, before which, water samples that may be used for VOC (volatile organic compound) or isotope analysis may be taken [13]. Sub-bottom anomalies are marked on the water surface by buoys on thin line and small weights, recorded by dGPS. We then probe over and into these anomalies on a rough 10 to $20 \mathrm{~cm}$ lateral spacing to the depth of the top of each anomaly (Figure 3): this minimises the problems of penetrating the target [14], yet maximises the chance of gas (scent) emission for the search dogs. 


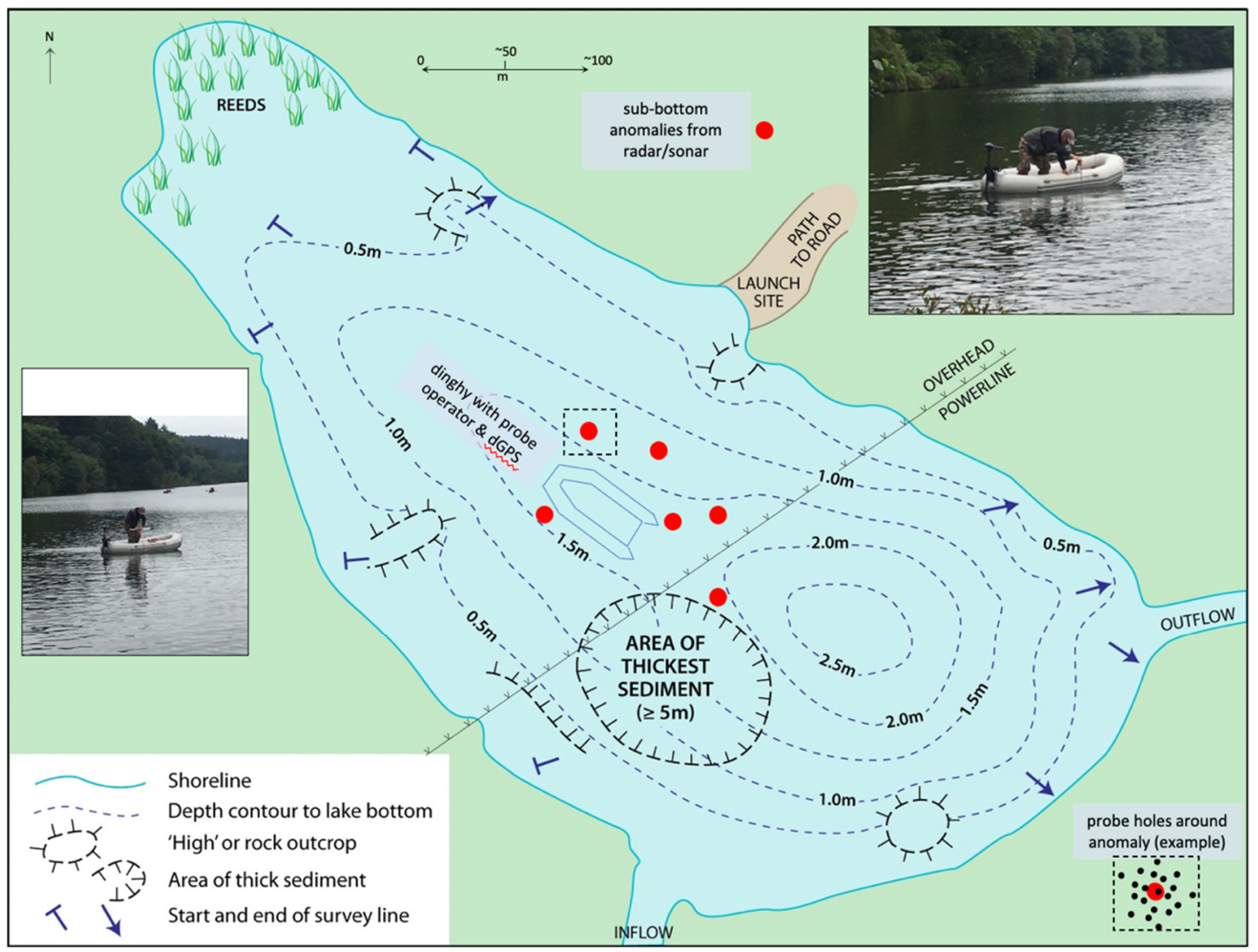

Figure 3. Suggested aquatic search method from a pond where a suspected homicide victim was weighed down and sunk. No precise scale is given to avoid location details: pond is $\sim 150 \mathrm{~m}$ long. Photograph inserts show probe deployment: each $\mathrm{WPR} /$ sonar anomaly was marked by a float (red dots) with a schematic of probe holes shown.

Any probe will suffice; we favour steel-tipped, and ideal are the van Walt peat probes (Figure 4), which come in $75 \mathrm{~cm}$ length extensions: probes longer than $\sim 2 \mathrm{~m}$ become unwieldy in a small boat, and potential hazards to boat users that may pierce inflatable craft. Prior to deployment of water-trained scent dogs [15], buoys maybe removed and their general location sailed over in a zig-zag manner from downwind to upwind; or buoys may be left, but control or 'dummy' buoys placed over areas with no sub-bottom anomalies as internal tests for the $\operatorname{dog}(\mathrm{s})$ and handlers - both remove bias and have advantages and disadvantages. A more focused search will then begin, starting from somewhere upwind of the designated search area, then zig zagging downwind where a 'no-indication' response would be expected until the emerging scent cone is again detected by the dog [15].

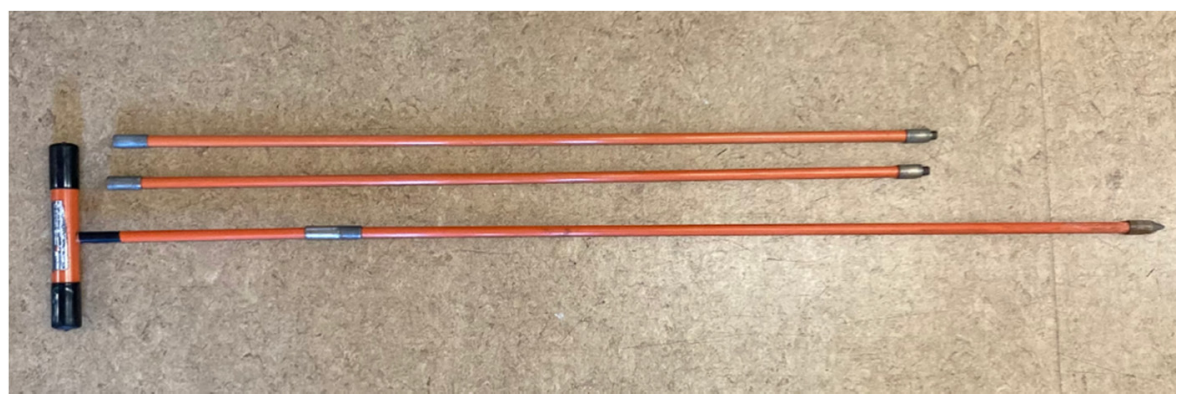

Figure 4. Van Walt peat probes (75 cm lengths) with steel tips-ideal for boat deployment in the search protocol suggested.

The effectiveness of water search dogs is, however, dependent on the appropriateness of the training aids used in their preparation [16-18]. For example, the odours of human 
decay are closely mirrored by those of human blood [16-18]. It is recommended that blood used in this capacity is best stored for up to 6 weeks at $4{ }^{\circ} \mathrm{C}$ or room temperature but not frozen [18]. On the other hand, and where legislation permits, human remains rather than porcine or chemically manufactured training aids are more apposite $[17,18]$.

\section{Recommendations}

The overall principles for using sonar, CHIRP, WPR, probes and water-deployed scent dogs are individually reviewed in published literature $[2,3,19,20]$. This work provides the first account of integrating these assets in the search for water-sunken and sediment-buried objects, most specifically, human remains. In death-related investigations, a multi-proxy approach such as we outline is (in our experience) considered good practice, in order to decrease the possibility of false-positives from any one method: no doubt other techniques, such as UAV-operated underwater cameras (in clear water), can be added. A suggested workflow for the application of our methods may comprise the steps below.

1. Background information (formerly known as 'intelligence') from search authorities (search and rescue; law enforcement; humanitarian organisations) is receivedproviding an indication of the search area.

2. Search area defined by specialists, considering hazards, water chemistry (e.g., conductive seawater/brackish water/ polluted areas), size/makeup of target.

3. Reconnaissance sonar of water body and its base gathered by boat or UAV/drone [12]: may provide an 'easy win' in location of the missing object/person.

4. Simultaneous gathering of CHIRP and radar (both can be deployed from one boat) data, viewed in real time with anomalies marked by dGPS and buoys.

5. Buoys should be subtle but observable from the water, with controls at locations with no anomaly, to avoid unconscious bias by dog and dog-handler.

6. Repeated sonar/CHIRP/WPR surveys over marked anomalies, to improve location accuracy-repositioning of buoys if needed.

7. Evaluation of anomalies, with a hierarchy of likely targets based on reflection characteristics, dimensions, depth, spatial location in the water body (close to shore, covert, access via perpetrator boat etc.).

8. Probing of sediment above and to the top of target anomalies (as in Figure 3): observation of gas bubble release.

9. Deployment of water-trained scent dogs 5 to 20 min after probing (depending on gas release): best practice being two or more dogs, each taken individually by boat and moved in a zig-zag manner from downwind of the target to upwind. The other $\operatorname{dog}(\mathrm{s})$ remain out of sight and earshot to be deployed independently $[3,4,15]$.

10. No consistent dog indication over targets allows buoys to be removed (locations are known from dGPS and stored in a geographic information system). If an individual object such as one human cadaver is the target, combined background, geophysical anomaly and dog indication are usually sufficient in terrestrial searches to prompt forensic archaeological investigation. In this work, this would involve divers investigating the sediment by hand, or the construction of a coffer dam to isolate water from the location and allow excavation by trained archaeologists/anthropologists/disaster victim response personnel.

\section{Further Work}

Whilst acoustic sub-bottom profiling devices may be used in any aqueous environment, data acquisition may be impeded or completely eliminated by weed growth and gas bubbles [20], while WPR does not suffer this limitation. Conversely, WPR is only successful in freshwater; even estuarine, brackish water becomes conductive enough to stop radar wave penetration and reflection. A future test of this proposed methodology may compare acoustic and radar responses from a forensic target or targets, just as Fuchs et al. [19] did for sedimentological studies of Swiss lakes. As with all geophysics, the balance between resolving target size and depth, but also target type and surrounding sediment, remains a 
problem. A small (e.g., less than $1 \mathrm{~m}$ ) target with good contrast to surrounding sediments (e.g., containing metal, gas, non-skeletonised remains) be it chemical or physical, will become hard to image at more than a few metres' depth. Likewise, targets with similar properties to the enclosing sediment may prove invisible: on the same search as shown in Figure 2, a minor target contact was made (Figure 5).

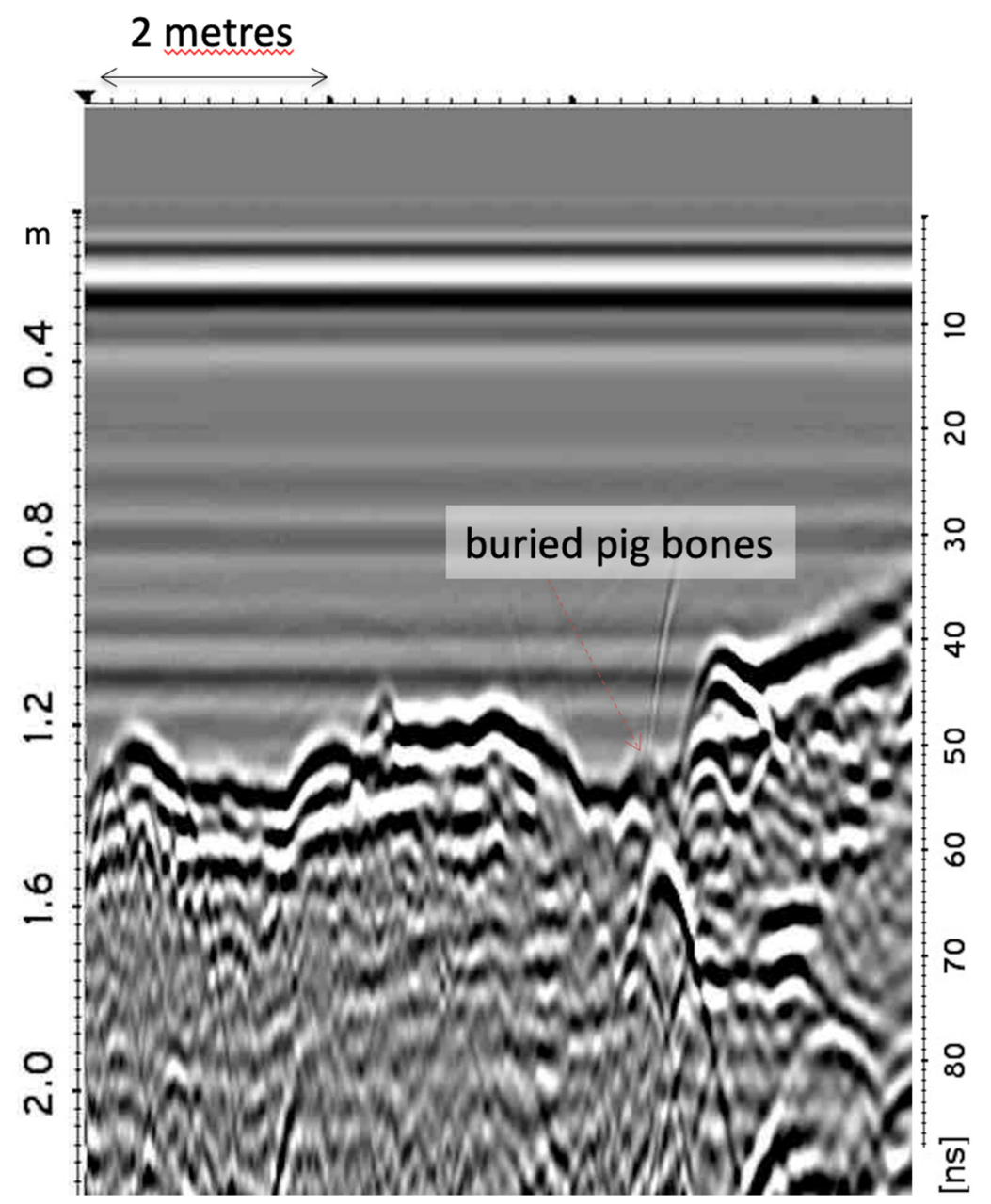

Figure 5. Selected water-penetrating radar profile from the canal search WPR data shown in Figure 2, with one very subtle anomaly, found to be a bag containing stones and pig bones. Data were gathered as in Figure 2, with a dinghy-deployed $450 \mathrm{MHz}$ Mala Geoscience High Dynamic Range GPR. Profiles depth converted using $0.032 \mathrm{~m} / \mathrm{ns}$, based on water conductivity measurements; $\mathrm{m}=$ metres, ns = nanoseconds (two-way time, right axis).

Due to its location at a canal access point, police divers used the anomaly as a test location and recovered pig (Sus scrofa, prob. domesticus) bones in a degraded bag with stones, some $15 \mathrm{~cm}$ under the sediment surface. Compared to the more apparent targets found in the survey, this would have been unlikely as a priority search location, the radar interpreter dismissing it as a human artefact from canal use or discard, or rock of dissimilar different makeup to the sediment. In retrospect, the search advisor may have been dismayed to see tens of buoys at this search location, following sub-bottom WPR or sonar surveys: yet when the speed and ease (usually) of probing soft sediment is considered, and the trained $\operatorname{dog}(\mathrm{s})$ eliminating targets, so this number diminishes to fewer locations, each of which has a GPS point or buoy for a dive/body recovery team. 
Author Contributions: Conceptualization, A.R.; methodology (canines), N.P. (geophysics/probes), A.R.; writing-original draft preparation, A.R. All authors have read and agreed to the published version of the manuscript.

Funding: NJP received funding from Epilepsy Ireland.

Institutional Review Board Statement: Not applicable.

Informed Consent Statement: Not Applicable.

Data Availability Statement: Original WPR data is available, on request to the Corresponding Author.

Acknowledgments: We are grateful for assistance from: detectives Brian Geddes and Pat Campbell (Police Scotland); Sergeant Tony Coombes (Derbyshire Police); Tony Corcoran (Northwest Dive Unit); Murray Haynes (National Crime Agency); Mike Ferguson (Home Office). Sergeant Fran Podger (Police Service Northern Ireland, dog handler) and Professor Lorna Dawson instigated parts of this work. Mike Langton (Mala Geoscience) provided advice, field (water) assistance and equipment loan. Two reviewers provided helpful comments: Reviewer 2 was especially insightful, who we especially thank. Greatest thanks go to Trevor Winton of Flinders University, who provided enthusiastic interest.

Conflicts of Interest: The authors declare no conflict of interest.

Abbreviations
$\begin{array}{ll}\text { The following abbreviations are used in this manuscript: } \\ \text { CHIRP } & \text { Compressed High Intensity Radar Pulse } \\ \text { Cm } & \text { centimetre } \\ \text { dGPS } & \text { differential Global Positioning System } \\ \text { GPS } & \text { Global Positioning System } \\ \text { GSSI } & \text { Geophysical Survey Systems International } \\ \text { Km } & \text { kilometre } \\ \text { M } & \text { metreMHz-megahertz } \\ \text { m/Ns } & \text { metres per nanosecond } \\ \text { nS } & \text { nanoseconds } \\ \text { Sonar } & \text { Sound Navigation and Ranging } \\ \text { TWT } & \text { two way (travel) time } \\ \text { UAV } & \text { unmanned aerial vehicle } \\ \text { WPR } & \text { water penetrating radar } \\ \text { VOC } & \text { volatile organic compound }\end{array}$

\section{References}

1. Imaizumi, M. Locating buried bodies. FBI Law Enforc. Bull. 1974, 43, 2-5.

2. Owsley, D.W. Techniques for locating burials, with emphasis on the probe. J. Forensic Sci. 1995, 40, 735-740. [CrossRef]

3. Judah, C. Water Search: Search and Rescue Dogs Finding Drowned Persons; Heritage Books: Berwyn Heights, MD, USA, 2011; 180p.

4. Rebmann, A.; Sorg, D.E. Cadaver Dog Handbook: Forensic Training and Tactics for the Recovery of Human Remains; CRC Books: Baton Rouge, FL, USA, 2000; 350p.

5. Snovak, A.E. Barron's Guide to Search and Rescue Dogs; Barron's Educational Series; Happauge: New York, NY, USA, 2004; 272p.

6. Armstrong, E.J.; Erskine, K. Water-Related Death Investigation: Practical Methods and Forensic Applications; CRC Press: Boca Raton, FL, USA, 2010; 388p.

7. Winton, T. Validated parametric sub-bottom profiler survey measurements of sediment cover over maritime archaeological test specimens: Their importance for in-situ management and archaeological research of underwater cultural heritage sites. Australas. J. Marit. Archaeol. 2019, 43, 3-25.

8. Lévêque, C. Lake and Pond Ecosystems. In Encyclopedia of Biodiversity, 2nd ed.; CRC Press: Boca Raton, FL, USA, 2000; pp. $458-466$.

9. Haglund, W.D.; Sorg, M.H. Human remains in water environments. In Advances in Forensic Taphonomy: Method, Theory and Archaeological Perspectives; Haglund, W.D., Sorg, M.H., Eds.; CRC Press: Boca Raton, FL, USA, 2002; pp. $201-218$.

10. Ruffell, A.; Parker, R. Water penetrating radar. J. Hydrol. 2021, 597. [CrossRef]

11. Bastien, N.R.P.; Arthur, S.; Wallis, S.G.; Scholz, M. Runoff infiltration, a desktop case study. Water Sci. Technol. 2011, 63, 2300-2308. [CrossRef]

12. Bandini, F.; Olesen, D.; Jakobsen, J.; Kittel, C.M.M.; Wang, S.; Garcia, M.; Bauer-Gottwein, P. Bathymetry observations of inland water bodies using a tethered sing-beam sonar controlled by an Unmanned Aerial Vehicle. Hydrol. Earth Syst. Sci. 2017, 25, 4549-4565. 
13. Irish, L.; Rennie, S.R.; Parkes, G.M.B.; Williams, A. Identification of decomposition volatile organic compounds from surfacedeposited and submerged porcine remains. Sci. Justice 2019, 59, 503-515. [CrossRef] [PubMed]

14. Stein, J.K. Coring archaeological sites. Am. Antiq. 1986, 51, 505-527. [CrossRef]

15. Powell, N. Search Dogs and Me: One Man and His Life-Saving Dogs; Blackstaff Press: Belfast, UK, 2011; 288p.

16. Rendine, M.; Fiore, C.F.; Bertozzi, G.; De Carlo, D.; Filetti, V.; Fortarezza, P.; Riezzo, I. Decomposing human blood: Canine detection odour signature and volatile organic compounds. J. Forensic Sci. 2019, 64, 587-592. [CrossRef]

17. Dargan, R.; Forbes, S.L. Cadaver-detection dogs: A review of their capabilities and the volatile organic compound profile of their associated training aids. Wires Forensic Sci. 2020, e1409. [CrossRef]

18. Forbes, S.L.; Rust, L.T.; Trebilcock, K.; Perrault, K.A.; McGrath, L.T. Effect of age and storage conditions on the volatile organic compound profile of blood. Forensic Sci. Med. Pathol. 2021, 10, 570-582. [CrossRef]

19. Fuchs, M.; Beres, M.; Anselmetti, F.S. Sedimentological Studies of Western Swiss Lakes with High Resolution Reflection Seismic and Amphibious GPR Profiling. In Proceedings of the 10th International Conference on Ground Penetrating Radar, Delft, The Netherlands, 21-24 June 2004; pp. 1-4.

20. Kovacs, A. Impulse Radar Bathymetric Pro-Filing in Weed-Infested Fresh Water; (CRREL) Report; USA Cold Regions Research and Engineering Laboratory: Hanover, NH, USA, 1991; 19p. 